\title{
Evaluating Education Information Systems: Implementation of Longitudinal Student Data Systems in Six School Districts
}

\author{
By Rebecca Hinze-Pifer \& Daniel S. Ramsey
}

Education reformers are currently spending significant resources and effort advocating for school districts to adopt integrated, longitudinal computer systems. They hope the systems will help teachers understand their students as well as adapt their teaching methods. Additionally, they argue higher-quality data will help administrators and policymakers determine if schools are successful. This paper describes the experiences of six districts as they adopted education information systems, discusses emergent themes based on their cases, and explores implications for policymakers and school leaders.

\section{Introduction}

Secretary of Education Arne Duncan (2010) has called education data "the compass that points reform in the right direction." In recent years, school districts have devoted millions of dollars to integrating and improving the computer systems schools use to store student data. Education reformers hope access to high-quality, timely information can inform and improve the decisions made by teachers, counselors, administrators, and policymakers. They envision an education system in which teachers regularly access information about class performance and adjust teaching methods in response; principals proactively monitor teacher performance using comprehensive and reliable data; and guidance counselors pinpoint students at risk of failure and target services accordingly. This article reports on an empirical study of how school districts implement the education information systems at the heart of these reforms.

\section{Background}

From standardized test scores to health records to demographic information, schools collect a large amount of information about students. As computers became integral parts of schools at the end of the 1990s, schools digitized student data and began using databases to organize student records. Currently, student records databases are widespread in American schools; however, they tend to be information silos that house information without making it easily accessible to relevant users. Furthermore, many school districts use several databases-one for attendance, one for grades, one for test scores, and so forth-that rarely are capable of communicating with one another. As a result, teachers and administrators cannot readily use these systems to drive instruction and school improvement.

Longitudinal education information systems, which first appeared with the advent of high-power, networked computer systems, integrate the disparate data schools collect about students into a single system. By tracking students from preschool through college, educational information systems make it possible for schools and districts to track how an indi- 
vidual teacher's students perform in subsequent years, identify students at risk of failure, and locate systematic failings in the education system. Furthermore, many systems are designed to help teachers evaluate what students are learning and what they aren't, and to facilitate communication between parents, teachers and students.

The US Department of Education has taken several steps to encourage increased use of longitudinal education information systems. Department leaders see data as vital to their reform efforts; in order to understand how schools currently use data, the Department commissioned several reports on the subject (Gallagher, Means, and Padilla 2008; Hamilton et al. 2009; Means, Padilla, and Gallagher 2010). The Department has provided roughly $\$ 60$ million to states for data system improvement in recent years. In addition, Race to the Top grant recipients may also use some of their $\$ 250$ million in grants to improve their education information systems. The strengths and pitfalls of using data in schools have also received substantial attention from both the academic and popular press (Aarons 2009; McCrummen 2010).

A variety of education information systems are available on the competitive market, and some school districts have chosen to develop proprietary systems. ${ }^{1}$ The study reported here examined the transition to an integrated data system in six school districts, five of which purchased commercial programs and one of which developed its own system.

The authors begin with a review of the academic literature on education information systems, followed by a description of their research methodology. The results of the study are presented first as individual studies of six school districts and then as broad themes that emerged from the districts studied. Finally, the authors draw several conclusions regarding the implementation and use of the systems at these districts and discuss the im- plications of their findings.

\section{Literature Review}

As technology evolves, school districts and software developers expand their notion of how it might be used to support instruction and evaluation. As a result, there is a range of commercially available education information systems (Wayman, Stringfield, and Yakimowski 2004). Although some authors make distinctions between types of systems, the research often refers to education information systems, student data systems, student data warehouses, or school data systems interchangeably.

\section{Uses of Education Information Systems}

One potentially promising use for education information systems is to support ongoing student assessment, especially by facilitating formative and summative assessments (Supovitz and Klein 2003; Zavadsky 2009). Such assessments can inform teachers about the progress of their class and individual students in meeting learning objectives (Marzano 2009). Teachers may be able to use education information systems to systematically track student performance, informing their decisions about their classes and individual students (Lasley 2009). In addition, surveys of teachers indicate that many report using education information systems to identify gaps in student learning. Based on the gaps identified, teachers may be able to adapt lesson plans, adjust the instructional pace, target activities to specific groups of students, or arrange for remediation with individual students (Gallagher, Means, and Padilla 2008; Supovitz and Klein 2003). These data can also assist in student placement through the course of their academic career, either in specialized programs or through the normal process of advisement and placement at the intermediate and high school level (Means, Padilla, and Gallagher 2010). Teachers may also be able to use education information systems to evaluate 
their own instructional practice. Analyses of class performance might help teachers better understand their own strengths and weaknesses, and plan for appropriate professional development activities, as has been observed in several districts (Brunner et al. 2005; Supovitz and Klein 2003). Teachers might also evaluate their instructional practice and identify promising methods to pursue further (Codding and Connell 2009).

Users of education information systems also report using the systems to facilitate communication between teachers, administrators, parents, and other stakeholders. With a more detailed understanding of each student's progress, teachers can hopefully better discuss the information with parents (Brunner et al. 2005; Gallagher, Means, and Padilla 2008). Teachers can also discuss student progress and instructional strategies with each other as well as with school staff and administrators (Brunner et al. 2005).

\section{Features of Education Information Systems}

Prior research suggests education information systems should have a variety of specific features in order to be successful. First and foremost, education information systems should compile and allow for the analysis of multiple data relevant stakeholders, especially teachers, administrators, and parents. The literature consistently refers to the same data elements, including student demographics, attendance, course grades, standardized test scores, formative assessment results, and the results of gifted education, special education, and English language learning (ELL) evaluations (Datnow, Park, and Wohlstetter 2007; Means, Padilla, and Gallagher 2010; National Center for Education Statistics 1997; Supovitz and Klein 2003). Reformers also suggest built-in benchmark assessment tools may be useful, by assisting with curriculum evaluation and teacher planning (Datnow, Park, and Wohlstetter 2007). In addition, inte- grating K-12 and postsecondary information systems can aid in the use of data in long-term evaluation and research efforts (Data Quality Campaign 2010).

A few additional data elements, like disciplinary information, appear occasionally in the literature (National Center for Education Statistics 1997). Electronic portfolios and other rich sources of student work also may be included (Supovitz and Klein 2003). In determining which data elements should be included in education information systems, advocates for systems typically focus on the extent to which the element could support teacher and administrator decision making, especially in terms of evaluating instructional practice and student learning.

In addition to having these data in an information system, a number of authors argue data should be readily available to teachers in order to support their instructional decisions. Much of the data now in information systems is available to teachers through other avenues; having quick, easy access to the data in real time may allow teachers to use data more effectively. Supovitz and Klein (2003) suggest real time information like attendance, grades, or benchmark assessment scores should also be updated frequently so that users can act while the information is still relevant, and Wayman, Stringfield, and Yakimowski (2004) conclude that a clear and intuitive user interface enhances data availability.

To allow for appropriate decision making, education information systems should provide users with data in a format relevant to them. In addition to developing preformatted reports for common activities, advocates argue education information systems should allow for more detailed queries and ad-hoc reporting to ensure that relevant data is easily accessible to the various user groups. Data systems can make information more relevant by aggregating and disaggregating data based on user needs (Wayman, Stringfield, and Yakimowski 2004). For 
example, reports produced from an education information system for a teacher may include information on both the overall class's performance as well as information on each student, allowing the teacher to understand student strengths and weaknesses at both levels of analysis.

\section{Challenges in the Use of Education Information Systems}

Despite the availability of desired features and valuable uses for education information systems, the literature suggests that several factors limit their current use in American schools. School leaders and others must consider these challenges when implementing education information systems, as the context of an information system's use can have a significant effect on the success of the system.

In designing systems, district leaders should seek acceptance and support from users early in the process. To do so, those implementing the system must consider user needs. Primarily, this means that data should be relevant and easily accessible to teachers with a wide range of aptitudes for technology and data usage (Datnow and Park 2009; Wayman, Stringfield, and Yakimowski 2004). In making data relevant, administrators should ensure that the data in the system is timely and sensitive to the curriculum of each teacher (Datnow and Park 2009). In order to receive "buy-in" from users, administrators must show that they value data usage, use data themselves, and establish a vision for how data should be used in the school or district (Copland, Knapp, and Swinnerton 2009; Wayman 2005). This attitude may be directly communicated to users, but is more often communicated through decisions about resource allocation, including both funding for the system and providing teachers time to use the system and analyze the information it provides (Hamilton et al. 2009; Datnow, Park, and Wohlstetter 2007; Ingram, Lewis, and Schroeder 2004; Wayman 2005). By making decisions that encourage data use, ad- ministrators are more likely to encourage authentic data use among teachers.

Inadequate training, professional development, or support systems can also hinder the use of education information systems (Datnow, Park, and Wohlstetter 2007; Datnow and Park 2009). Training and professional development efforts must address two primary concerns: providing sufficient initial training as well as ongoing support for teachers. First, training on how to use the education information systems is needed, but is often insufficient on its own. Teachers also need professional development regarding how to use the information that the system generates and how to apply it to instructional decision-making (Wayman and Cho 2009). This is more challenging, and often ignored by those implementing education information systems. Second, in addition to initial training when the system is adopted, districts and schools must also provide ongoing support (Datnow and Park 2009; Wayman and Cho 2009). As before, this involves supporting both the education information system itself as well as the use of data in general. These two levels of support require the efforts of information technology, training, and curriculum personnel on the district level, as well as the cultivation of especially skilled users who can assist others in using data.

User attitudes can also inhibit the success of education information systems. Users' concerns about the linkage of education information systems to accountability policies, testing systems, and a general narrowing of the curriculum may lead to resistance (Ingram, Lewis, and Schroeder 2004). To overcome this, school and district leadership must seek "buy-in" from teachers early and often in the process of adoption. Implementers of education information systems should also consider establishing safeguards to allay these fears, such as limiting access to assessment data. Despite high expectations for education information systems and concerns about potential challenges in im- 
plementation, the literature suggests successful implementations are possible. This study sought to understand how school districts navigate the implementation process, in order to improve understanding of how such successful implementations can occur.

\section{Research Questions}

The researchers developed questions to probe issues present in the literature and generate a concrete sense of how system adoption works at the district level. The central research question addressed by this study is: How do the users of currently functioning education information systems perceive the information and features provided by those systems? The scope of the study was limited to teachers and district evaluation personnel involved in supporting teacher use of the system.

To address the central question, this study considered the following research questions:

- What process did school districts use to select an education information system?

- What features or other factors did school district leaders feel were important considerations in the selection process?

- How did school districts train teachers about the system?

- What expectations did principals or other school leaders establish regarding how teachers should use the systems?

- What features do teachers feel are most useful in the adopted education information system? Are there any they would like to add to the system?

- What features do teachers not use? Why?

- What types of assistance do teachers believe they need to increase their use of the information provided?

\section{Guiding Framework}

Proponents of education information systems argue these systems can improve the quality of performance data available to teachers, families, school leaders, and other interested constituencies when well implemented. The research questions are designed to probe teacher usage patterns and determine if they are consistent with the theory that teachers will be able to use improved data about student performance to influence and improve their teaching.

The authors developed a model to visually represent the processes that underlie education information system design and operation, according to advocates for the systems (Figure 1). The study design probes the assumptions inherent in this model in order to understand the ways in which education information systems may affect classroom instruction and, ultimately, student performance.

The columns in the model represent the stages in the system's use. The first column shows specific types of data that are inputs to the system. The next column shows key aspects of highquality education information system design. The outputs column lists examples of the types of information users should be able to get from a system. The model distinguishes between outputs, which are the actual products produced by the data system, and actions, which are the theoretical occurrences that follow from the outputs, hopefully helping schools reach their goals. For example, the education information system may be able to produce a report showing how many students in a class are struggling with a particular concept (an output), which the teacher could then use to target instruction to correct the deficiency (an action), which may result in improved student performance (a goal).

Education information systems may not be successful due to factors outside the control of the system's designer. A number of these mediating factors are listed at the bottom of Figure 1. For example, the education information system may be well-designed and may be capable of pro- 
76 • Evaluating Education Information Systems

Figure 1: Education Information Systems Guiding Framework.

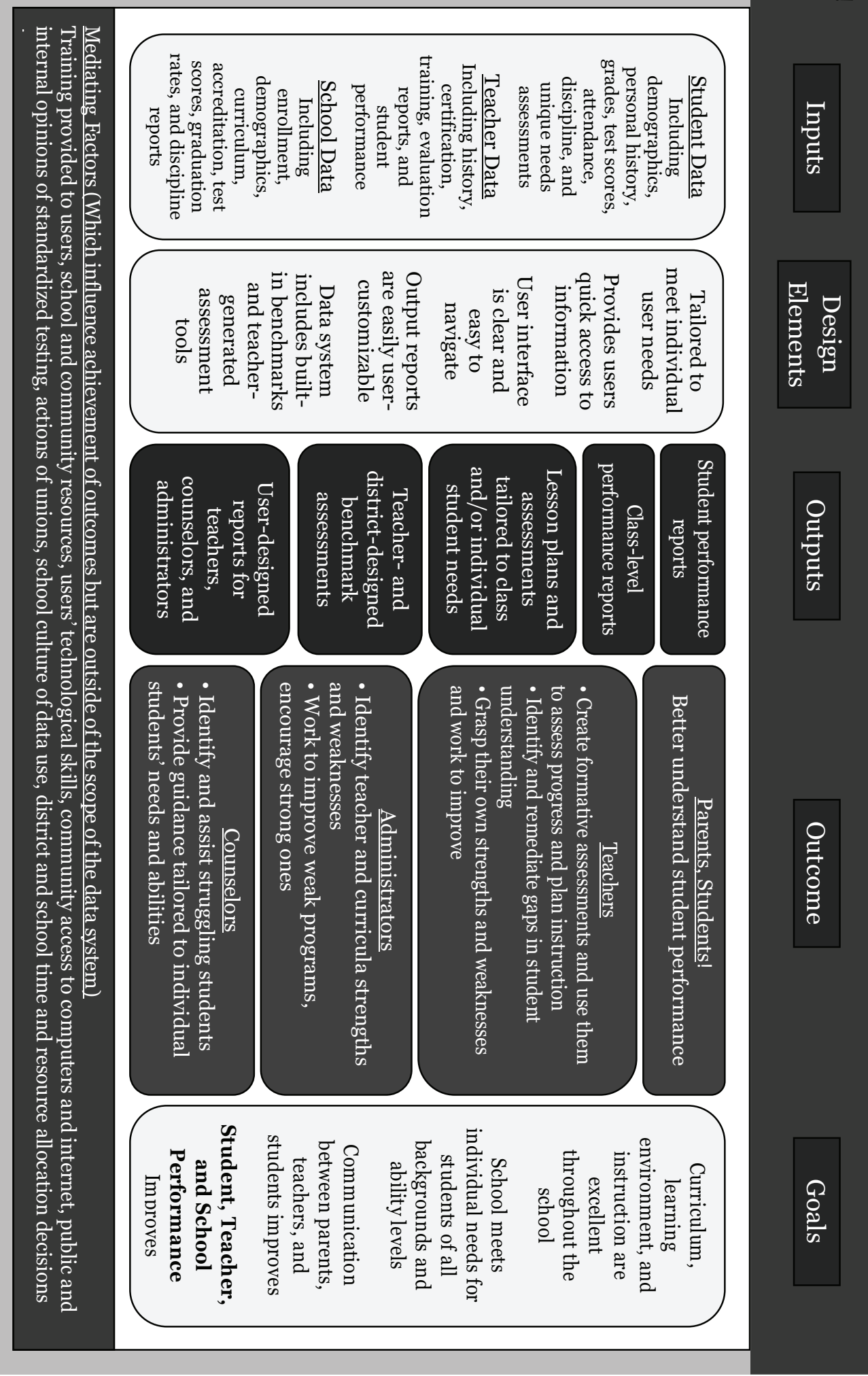

Source: Authors' analysis. 
ducing changes in teacher behavior and student outcomes, but not achieve those goals because teachers did not receive sufficient training or support in how to use the system.

\section{Scope and Methods}

This study probed three areas of system use in the districts studied. First, it probed which design elements school leaders find important to program functioning by examining decisions made when selecting systems. Second, it considered whether the results obtained are attributable to mediating factors or imperfect implementation by asking questions about aspects of the implementation process like teacher training. Finally, it tested the connections between outputs and actions by asking teachers about their actual use of the systems.

The researchers combined information from the academic literature with studies of six school districts to address the research questions. The team based its conclusions on a review of academic and government publications, interviews of district staff at six districts that have adopted education information systems, and surveys of teachers at two of those districts regarding their use of the systems. The literature review and interviews served dual purposes; they both provided data and informed the development of the survey instrument. The survey is the primary source of information about how teachers use education information systems.

\section{In-Depth Interviews}

To understand the process districts used to select and deploy education information systems, the research team conducted eleven in-depth interviews with district staff responsible for data system adoption. The interviews included questions about the selection, adoption, and implementation processes used by the district, as well as information on major uses of the system and available feedback from users. The researchers asked interview- ees for other relevant staff members to interview, especially those involved with training or supporting users, and conducted ancillary interviews with identified individuals. Although the results of these interviews are not generalizable to all districts, they provide a detailed portrait of the issues surrounding the adoption and use of the individual education information systems, give context for understanding how in each district implemented the system, and informed the development of the survey instrument.

\section{Surveys of Teachers}

Results related to user behavior and experiences are based on surveys of teachers in two districts using different commercial education information systems. The surveys asked teachers questions about their background, the training and support they received in using the system, their opinions of the usability of the system, and their usage patterns. The surveys asked the same questions for all teachers in both districts, and were administered using an online commercial survey service. Throughout the process, the researchers remained cognizant of the limitations inherent in using voluntary surveys, including potential selection and response bias from respondents.

The research team requested permission to survey teachers at each of the districts included in the interview process. In most cases, this required a formal request to conduct research in the district. Where necessary, the team received approval of relevant district administrators. The researchers then worked with the district to find an appropriate way to administer the survey to teachers, through either emails or embedding a hyperlink to the survey in the web portal used to access the information system. In both districts surveyed, the survey was available to the entire population of teachers who used the system in the district.

Each of the four districts that were not surveyed had unique reasons the sur- 
vey was not conducted. District staff at the district with a proprietary system were concerned the survey would interfere with their own evaluation efforts. One district's research approval process would have taken almost a year to complete, which was outside the scope of this study. Another approved the research but was unable to provide teacher contacts in sufficient time to deploy the survey before the end of the study. Finally, one district had not given its teachers access to the system at the time of the study. Although these survey deployment challenges limited the scope and richness of the final data set, the survey results from both districts were remarkably consistent with one another, providing a valuable supplemental data source on which the team could base its findings.

\section{District-Level Studies}

After considering a number of nationally competitive and widely used education information systems, the authors selected four information systems for inclusion in the study (three commercial systems and one district-developed, proprietary system). For the commercial systems, the researchers obtained the names of clients either directly from the vendor or from publicly available sources, and then contacted information technology and evaluation staff at those districts. The team contacted staff at ten school districts; six districts agreed to participate and are described in Table 1 . The researchers collected data during the spring of 2010.

In selecting districts, the authors sought to ensure diversity in terms of district location, size, and demographics; however, as selection process was not random, the sample should not be interpreted as representative of the population of education information systems users. In selecting districts, the researchers often relied on reference lists and case studies provided by vendors. In addition, district personnel had to be willing to devote time to phone interviews and be willing to work with the researchers to secure permission to survey teachers. The help of vendors and district personnel was crucial; however, it also introduced the possibility that results may be overly positive, as vendors may have provided information on only those clients that had a good experience with the product. Furthermore, districts likely purchase systems that match their needs and change vendors if they are unsatisfied. As a result, it is difficult to determine how well each system would perform outside the context of the school district studied.

\section{Cases}

Case 1: DataDirector in a Small Midwestern District

In this district of fewer than 8,000 students, a single staff member was responsible for managing the DataDirector adoption and implementation process. At the beginning of the 2008-2009 school year, the district decided to abandon its use of Pearson Inform because that program did not provide the features they expected and was unpopular with teachers. The district staff member responsible for evaluation solicited input from district leadership about desired features, finding they wanted a longitudinal data system with the ability to connect student data across information silos, disaggregate student performance data on a variety of dimensions, and provide teachers rapid feedback after benchmark testing. She also indicated they prioritized finding a system that was easy for teachers to learn and use routinely. To that end, she used volunteer teachers and principals to test several different systems and spoke with peers in other school districts.

The district began its implementation of DataDirector at the beginning of the 2009-2010 school year. The district evaluation coordinator used a rolling training model, starting with elementary schools, followed by the high schools midyear. She planned to begin training middle 
Table 1: Characteristics of Districts.

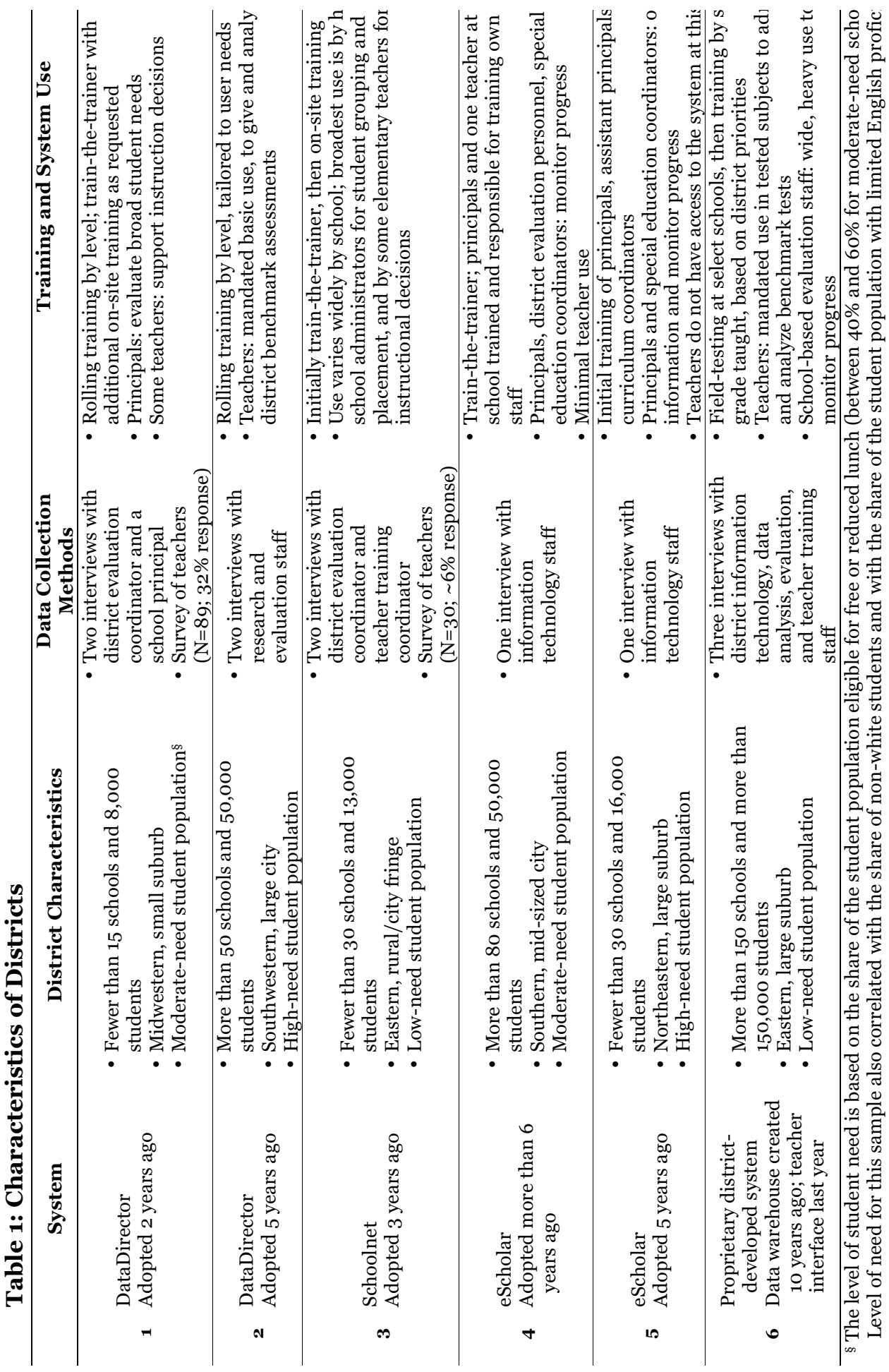

Source: Authors' analysis. 
schools to use DataDirector at the beginning of the 2010-2011 school year. She first trained all of the principals, in a setting where each principal had a computer, was able to enter data, and had access to reports for his/her own school. If principals felt comfortable with the system, they provided training directly to the teachers at their schools; if principals were uncomfortable with the system, the district-level trainer went to the school and provided direct teacher training. She also provides phone support for teachers and is available for on-site individualized training as requested by teachers. Training remains ongoing; comments on the teacher survey suggest some high school teachers are not fully trained and anticipate using the system more after receiving additional training.

Survey respondents generally had a positive impression of DataDirector's ease of use, speed, and efficiency. Approximately half reported that they use DataDirector at least occasionally to track class progress in meeting learning objectives (59 percent), inform lesson planning (58 percent), set goals (48 percent), track individual learning (44 percent), or look at student performance by subgroup (43 percent). Generally, teachers reported that they used DataDirector to look at student performance as a class more than to evaluate individual student performance. Furthermore, of teachers expressing an opinion, approximately 60 percent indicated they would use DataDirector to generate information on students' past performance at the beginning of the next year.

The majority of teachers (72 percent) said that they used DataDirector less than 15 minutes each week. Teachers also reported strong data culture in their schools: 84 percent said the administration encouraged teachers to use data and to collaborate to use data. However, only about half said that school leadership sufficiently trained teachers on how to use data (56 percent) or set aside time for teachers to evaluate student performance data (45 percent). Survey respondents were either unfamiliar with or had a negative impression of DataDirector's custom reporting and benchmark assessment capabilities. Finally, teachers whose classes did not include state standardized assessments reported they either had not been trained (predominantly high school electives teachers) or had received training, but did not believe DataDirector was appropriate for use with their students (predominantly early elementary grade teachers).

The district uses DataDirector to meet program evaluation requirements for federal and state testing evaluations. At minimum, school principals use the system to gather evidence for school improvement plans. The researchers did not communicate directly with principals, but district evaluation staff suggested that principals use DataDirector for several other administrative and evaluation purposes.

\section{Case 2: DataDirector in a Large Southwestern District}

This large district began its adoption of DataDirector five years ago; it had used the SchoolMax system beforehand. District leaders decided to switch programs because they wanted a system that could provide teachers and administrators immediate access to formative and summative assessment data that could be aggregated and disaggregated on a variety of dimensions. They also wanted to be able to monitor an individual student's progress over multiple years and design their own reports. Interviewees suggested the district chose DataDirector because the developer was willing to assist with implementation and design custom reports for the district.

The district's research and evaluation staff provide training and support for DataDirector. The district began its implementation at the secondary level and later expanded the system to the intermediate and elementary levels. In addition, the district offered several levels of training de- 
pending on user needs, with specific levels of training required for certain types of users. The implementation process began with general training about the purpose and goals of the system for district and school administrators, followed by training on the system by the director of the research and evaluation office. Users were given access to the data only after they completed training. Advanced training was then provided to assistant principals, department chairs, and resource teachers. Finally, the district required a basic level of training for all teachers.

Interviewees felt the most common use of the system was to give and analyze district mandated benchmark assessments. The district conducts benchmark assessments throughout the school year, and teachers are strongly encouraged to use DataDirector to analyze the data generated by the assessments. Teachers are also required to discuss data with an administrator periodically, which encourages usage of the system. The evaluation staff interviewed also suggested that teachers use DataDirector to access demographic data about their classes and individual students. They indicated upper elementary teachers used the system most of all teacher groups.

The district's staff also identified several features that DataDirector lacked or that could be improved, including a more intuitive user interface, expanded test bank items aligned to state standards, greater compatibility with the state's exit examinations, and the ability to retain student data for students who move out of the district and then return.

\section{Case 3: Schoolnet in a Mid-sized Eastern District}

This district began its adoption of Schoolnet three years ago. According to district evaluation staff, the search for an education information system evolved through several stages. District leaders initially looked for a system that could aggregate and analyze data related to the
No Child Left Behind Act requirements before the data became publicly available. After meeting with Schoolnet representatives, district staff became interested in using the system to perform analyses and inform education decision-making. In the final phase of adoption, staff wanted a system that could perform a wide range of analyses, including identifying longitudinal trends and breaking down standardized test scores by educational standard, teacher, and demographic group. The district is currently in the process of expanding its use of Schoolnet. Within the next year, the district plans to integrate its gradebook, attendance, and other student information functions into the system.

The district initially used a trainthe-trainer model, in which lead teachers were trained centrally and then became responsible for training others at their schools. The district switched to a job-embedded training model after a year, when staff realized that the school-based trainers did not have sufficient time or knowledge to perform the trainings. Most survey respondents (74 percent) received at least two hours of training; 33 percent received more than a day. Approximately 60 percent of respondents felt that they needed additional training.

District evaluation staff report that different school levels use Schoolnet in different ways. They see elementary teachers as more likely to use Schoolnet to monitor student performance, identify struggling students, and drive instruction. At the high school level, they suggest that Schoolnet is more a tool for administrators, who use it to group students, identify at-risk students, and find students who should be recommended for advanced courses.

Although the survey respondents are probably not fully representative of all teachers in the district, survey results regarding teacher use of Schoolnet were remarkably consistent with the survey of DataDirector users described in the first district. $^{2}$ Most users reported limited 
weekly use of Schoolnet (73 percent used it for less than 15 minutes each week), and the most frequently used features were tracking class progress, tracking individual student progress, and disaggregating performance reports by subgroup. Few users (less than 20 percent in all cases) reported using any of the individual features more than once a month. Respondents did report that they would use the system to learn about their incoming class at the beginning of the next school year.

\section{Case 4: eScholar in a Large Southern District}

The district began its adoption of eScholar more than six years ago. The district hoped to adopt a system that would allow for longitudinal analysis and ad hoc reporting of data from several preexisting data sources. According to the staff interviewed, the district wanted a program that would conduct longitudinal analysis connecting a variety of data sources, aid in assessment of student learning, and work with the districts' existing information systems. District staff also sought a system that could grow and evolve for different reporting needs as they arose.

Training and support for eScholar is provided by the district's information technology staff and certain school administrators and designated teachers. The district began its implementation by training principals in each school. Next, a technology mentor (usually a teacher) was trained for each school. Principals and technology mentors were then responsible for conducting training at their schools.

District staff believe eScholar is most often used to access demographic, enrollment, attendance, and assessment data. The district's reporting tool generates reports; most reports have to be developed centrally, though information technology staff attempt to develop reports as requested by users. Teachers have access to information on student assessment levels, achievement, and demographic composition to aid in planning at the begin- ning of the year. Teachers can also look at data at the individual student, group, and class levels. Although some teachers use the system, many do not. The interviewee indicated principals are the most common users. He also suggested district evaluation personnel and special education coordinators use the system.

In addition to longitudinal analysis and benchmark assessment, eScholar is tied into the professional development system, the registration system, and early childhood information, which facilitates interaction between these systems and allows for reporting from each of these sources from a single system. Following implementation, the district realized unexpected benefits, including a reduced amount of data entry stemming from decreased duplication of records.

\section{Case 5: eScholar in a Small Northeastern District}

This district adopted eScholar approximately five years prior to this study, and remains in the midst of the implementation process. District information technology staff have trained principals, assistant principals, and curriculum coordinators. At the time of the interview, the district had not provided training or access to eScholar to teachers; district staff did not indicate if or when this would occur. Of the six districts studied, this district was clearly the least successful in its implementation; it is included here to demonstrate the challenges districts-especially high-need districts-may face as they adopt education information systems.

In adopting a data system, the district hoped to be able to perform longitudinal analysis of its students' progress over time, which was not possible with its previous system. The district's student information systems director said the district wanted to connect a variety of data, including assessment, attendance, grades, and individual education plans, allow for queries at any level of detail, and allow for 
growth and expansion of new and historic data.

Although the district adopted the system five years ago, implementation remains in its early stages, and use has been limited. eScholar is most often used by school administration to access assessment, attendance, and grade data, as well as by special education staff to organize information in individual education plans. Moving forward, the district is considering what capabilities to pursue next, including additional assessment capabilities or support for the development of education plans for at-risk students outside of special education. However, the district has had difficulties deciding the best way to move forward, apparently due to a combination of district leaders placing a low priority on the system and limited staff in the district office. The district has not yet determined if it ever will provide teachers access to the system.

\section{Case 6: A Proprietary System in a Large Eastern District}

Due to its size and resources, this district has substantial in-house technical expertise and began the move to education information systems earlier than any of the other districts studied. According to district information technology staff, the district's superintendent in the mid199os pursued an initiative to help school leaders use data to inform leadership decisions. The district decided to develop its own system because there were no satisfactory commercially available products at the time; interviewees suspected the district would have purchased a commercial system, given the option. The resultant system was primarily a student data warehouse - a single, large database that compiled student information from a variety of sources. The district used a collaborative process to determine system specifications, including meetings with assistant superintendents and principals. It was designed to provide information to school leaders, but not to teachers.
After the No Child Left Behind Act mandated dramatically increased standardized testing, district technology staff began updating the system to support teacher-level users. According to a schoolbased testing specialist who used the original system for more than five years, the original system was very powerful, but the user interface required a high degree of technical expertise. The new system uses the existing data warehouse, but contains more detailed assessment information, allows for teacher-level users, includes standards-based assessment questions, allows teachers to generate their own assessments, and provides a more user-friendly interface.

The district field tested the new system at volunteer schools and then selectively trained teachers in certain tested subjects. In those subjects, teachers were required to use the system to administer district-developed quarterly benchmark assessments. After its first year, teachers district-wide were given access to the system and could ask for training. At the beginning of the 2009-2010 school year, all teachers were encouraged to start using the system, and, in February of 2010, teachers district-wide were trained on the system during a teacher in-service day.

District evaluation staff indicate that teachers are using the system widely, which they attribute to the fact that teachers are required to by school administrators. Interviews suggest that the system has more assessment resources and is a more natural fit for some subjects and grade levels than others. Although the individuals interviewed did not have sufficient knowledge to indicate teachers' level of satisfaction with the system, they did feel that some teachers were using it to inform instruction.

Interviewees identified a balance of positive and negative facets to the district-developed system. On the one hand, the system can be continually improved and customized to meet district-specific needs. Information technology staff are 
able to respond quickly and inexpensively to requests for new features. On the other hand, the system is continually evolving, and was available to users before it development was completed. Some interviews suggested that early users might have been discouraged from using the system by experiences with the initial versions.

\section{Key Findings}

Although results varied between the studied districts, common themes emerged; these will be described in this section. The subsequent section discusses implications of the findings for school districts, system developers, and policymakers. All of the districts studied used a collaborative process to select a data system, involving a number of stakeholders - although not always the same ones. Districts' information needs varied but commonly focused on providing greater access to student information, including the ability to perform and analyze student formative and summative assessments, and the ability to track student progress over time. Districts' approaches to training teachers also varied; districts most often trained specific school staff, who were then responsible for training the users at their schools.

In the surveyed districts, teacher use of information systems typically was limited to gathering information on the incoming class and giving standardized assessments. Survey results suggest two factors depressed teacher use in the districts studied: time constraints and inadequate training. Teachers reported that school leaders strongly encouraged the use of data, but often did not follow through with the time, training, or administrative support. Many survey respondents also reported their use was limited because the systems were difficult to navigate or time consuming to use.

\section{Adoption AND IMPLEMENTATION}

Districts have unique needs and prioritize a variety of different features when they adopt education information systems.

Although the specifics vary by district, district leaders overwhelmingly wanted users to be able to access timely data from a central source. District leaders in all the districts studied expressed the hope that the education information system would facilitate data-informed practice. The limitations of previous systems often drove the decision to adopt a new education information system. District staff wanted existing, separate systems integrated, and improved access to data analysis tools. When the district staff consulted potential users, they indicated that they wanted better access to grades, assessment results, attendance, and demographic information. Additionally, district leaders wanted systems that retain and analyze longitudinal data, especially when students transfer schools or advance from one level to the next, as several administrators noted that previous data systems did not allow for the retention of data from year to year. The timeliness of data availability was also a concern because users have to make decisions in a constantly evolving environment. Several leaders and users noted that teachers need the results of benchmark assessments within hours or days in order for them to be useful, and sought data systems that would allow this. Ease of access and use were also significant concerns of district leaders, in recognition of teachers' limited training and time. With few exceptions, district staff expressed satisfaction that the products they adopted meet these needs.

\section{Adoption and implementation is a collaborative process.}

Districts used a variety of collaborative processes to select education information systems. Typically led by information technology staff, evaluation staff, or a combination of the two, the districts also involved other leaders, including 
principals, curriculum and assessment coordinators, counselors, and teachers themselves. However, the level of involvement for each group varied from district to district. Although other stakeholders have a role in identifying requirements and reviewing proposed systems, one or two individuals usually made the final adoption decision. User groups were most involved when districts chose to customize education information systems or develop in-house report templates.

Districts use a variety of approaches to train teachers, all of which take time.

Most of the districts studied used a train-the-trainers approach, in which program vendors train a few district staff members, and then district staff train certain school staff, especially principals, technology coordinators, or designated lead teachers. Trained staff members were then responsible for conducting training at their individual schools. In some of the districts, however, district staff provided the training directly to teachers. In at least one district, the designated schoollevel trainer could ask district staff to conduct the training if he or she was not comfortable enough with the system. Both our interviews and surveys indicated that the individual who conducted the training, regardless of level, tended to become responsible for providing additional support as teachers begin to use the system. Regardless of approach, the training and implementation process took at least two years or more in all the school districts studied.

SYSTEMS

The literature suggests education information systems may have many features and a broad range of users; however, commercially available systems do not include all of these features, and districts rarely engage all potential users.

The education information systems studied generally included student performance information, but often did not include all of the features discussed in the literature. The most frequent omissions are student discipline reports and information on unique student needs (e.g special education, gifted, English language learners, students with disabilities, etc.). In some cases, features were available from the vendor, but the school district chose not to purchase the feature, due to either financial constraints or a desire not to overwhelm users. Furthermore, the range of users was rarely as broad as the literature suggests. Parents and students did not have any access to the systems, teacher access was sometimes limited, and interviews suggested that districts did not specifically train or provide access to other target users like guidance counselors. In districts studied, the district determined the user group based on district leaders' goals and reasons for adopting the system.

\section{Different types of teachers have access to different system features.}

The education information systems studied universally provided teachers in tested subjects such as math and language arts with standards-based assessment items, released questions from past standardized tests, and other curriculum resources. Fewer resources typically were available for teachers in non-tested subjects such as physical and social sciences. All of the systems allowed teachers to generate their own test questions, but typically included few or no system-provided test questions for teachers in non-tested subjects. Few teachers in non-tested subjects reported using these features. Some districts required teachers in non-tested subjects to use the systems; others only trained these teachers to use the system if they expressed interest. District policies also varied regarding the extent to which special education and teachers of English language learners were expected to use the systems. 
TEACHER UsE

Teachers' use of education information systems is often limited to gathering information about students and analyzing assessments.

Although a majority of surveyed teachers reported using the district's education information system, usage was often uneven between different types of teachers and generally confined to a few specific uses. The most common use reported in surveys and interviews was obtaining information about the incoming class, which typically included looking at students' past grades and standardized test scores in related classes. In two of the districts for which a teacher survey was not possible, interview data suggest a similar pattern.

In addition to accessing information about students at the beginning of a school year, some teachers also used education information systems to analyze assessment information about the students in their classes. When assessment items are computerized and tied to specific education standards, teachers can track individual and class progress toward objectives to inform their lesson planning. District leaders frequently discussed this as a major goal of adopting the system. In the first district studied, approximately half of the teachers reported that they used DataDirector at least occasionally to track class progress in meeting learning objectives, inform lesson planning, set goals, track individual learning, or look at student performance by subgroup. Tracking class and student progress was a primary use of the system for many users, though more teachers reported tracking overall class performance more often.

Most districts report providing a library of assessment questions in the system for teachers to use, although the emphasis of these libraries is on subjects with state-mandated standardized tests. Accordingly, teachers with these classes used the assessment tool more than others. Although the systems usually provided the capability for teachers to create, administer, and analyze their own assessments, few teachers reported using this feature. Open-ended survey responses suggest some teachers find that even when they are available, assessment libraries may be time consuming or difficult to use.

Teachers may lack the time, training, or support to use advanced features of education information systems.

Both surveys and interviews suggested that district leaders and principals established very high expectations for education information system use. In most districts, interviewees report superintendents, principals, and other leaders repeatedly encouraged teachers to use data to support instructional decision-making. However, leaders rarely matched their intentions and expectations with the provision of training, dedicated time to use data, and staff support. In order to encourage use of the systems, several districts did require regular discussions between teachers and school leaders about the results of assessments.

The teachers surveyed varied in the amount of training they received. In one district, most teachers reported receiving less than two hours of training; in another, most reported receiving a day or more of training. In both cases, teachers report being somewhat prepared to use the system. This limited level of support appeared to continue as teachers use the system. Although teachers reported a variety of institutional supports, including advanced users within their schools, school information technology staff, and district phone technical support, teachers in the surveyed districts felt district and school leadership had not set aside sufficient time for teachers to use the system and interpret data.

\section{Implications}

Research indicates education information systems may be powerful tools for streamlining student data and 
informing educational decision making on the district, school, and classroom levels. However, this study suggests districts must address substantial implementation hurdles to realize the full potential of an education information system. The findings from this study have implications for district and school leaders, education information system developers, and policymakers.

\section{Implications for School Leaders}

Districts have a range of needs and abilities related to education information systems. Districts should carefully evaluate those needs and work with system developers to determine how well a system will meet their requirements. In addition, districts should seek to adopt systems with the potential to expand to meet their needs as they evolve.

During adoption, district leadership should be cognizant of the district's capacity to implement the systems fully. The implementation process takes both time and resources. The extent to which a district is able to realize the potential benefits from an education information system will depend on the district's existing information technology and evaluation infrastructure and staff skill levels. Both the second and fourth districts studied were of low-performing, high-need districts. Although these districts had adopted the education information systems earlier than other districts studied, they appeared to have lower levels of implementation and penetration of use to the teacher level.

If leaders want teachers to use data to inform daily classroom instruction, teachers need training in both using the system and interpreting the information it generates. Teachers also need routine, dedicated time to analyze data and prepare new or modified lessons. It also is notable that the two more successful implementations, with the highest levels of classroom penetration, relied on the district staff to provide training to the teachers directly rather than using a train- the-trainer approach. In addition, even in districts with high reported teacher usage, teachers seem to have difficulty using advanced system features.

\section{Implications for System Developers}

For implementation to be successful, system developers should work with districts to ensure that the system will meet their particular needs, as failure to do so may lead to under-use of the system. During this process, developers should be cognizant of all the target user groups for the system and work to ensure their needs are met. In several cases, districts had decided to switch systems after adoption when the system did not meet the needs of all users.

Ease of system use was important to all users and districts studied. Systems should be designed with the recognition that most users will need to use a wide variety of features, but do so relatively infrequently. This consideration is especially important for districts in which teachers are important users, as teachers often have limited training and time to use the system. Given that teachers tend to use basic features of education information systems and tend to report difficulty with using more advanced ones, developers should place greater emphasis on usability of advanced features by developing systems that are closely aligned to teachers' needs and time constraints.

Finally, vendors should design systems with expansion of features and user groups in mind. In several cases, districts expanded their use of the system over time as internal capacity and data culture increased. Although the commercial market today may not support full integration of all the features discussed in the research literature, districts may increasingly demand these features in the future.

\section{Implications for Policymakers and Researchers}

There is no single education data system capable of meeting every dis- 
trict's needs. While the districts studied had some similarities in the features they wanted, they established different priorities and engaged different users in the adoption process. In addition, the features districts looked for evolved rapidly with technological advances and leadership shifts. Policymakers should establish policies that help districts and schools develop internal capacity and encourage data use without heavily constraining districts' abilities to establish priorities regarding features. Furthermore, policies that encourage teacher use of data systems should provide sufficient time and resources for training and substantial ongoing support.

As the market for education information systems evolves, policymakers may want to encourage common database standards to facilitate compatibility between systems and comparisons between districts. For example, the US Department of Education's “Basic Data Elements for Elementary and Secondary Education Information Systems" can be used as a basis for defining the various data elements shared by all systems. The Department can also incentivize system designers to design databases such that data can be transferred between systems when districts update or switch providers.

In order to inform further development of these systems, future research should seek to determine which features teachers and other users actually use. As systems are updated, vendors and district leaders should consult with users to determine how the system can be improved. Finally, further research and dialogue between vendors, district leaders, users, and researchers would clarify why some features proposed in the academic literature are either unavailable or underutilized.

\section{Conclusion}

Advocates for education information systems argue that they can be used in various ways to support classroom instruction and administrative decision-making. However, districts confront various challenges in adopting systems, including teachers' capacity for integrating the systems into their daily practice. As policymakers continue to encourage the adoption and use of these systems, they should be cognizant of the limitations as well as the unique needs of different users. Future research should endeavor to determine what support structures teachers need to draw robust conclusions about their students and adopt data-driven instructional methods. Additionally, further research may illuminate successful ways of structuring data systems to support their use in evaluating educational interventions and facilitating comparisons between schools and over time. 


\section{References}

Aarons, Dakarai I. 2009. "Leading the Charge for Real-Time Data.” Education Week 28(33): 25-27.

Brunner, Cornelia, Chad Fasca, Juliette Heinze, Margaret Honey, Daniel Light, Ellen Mandinach, and Dara Wexler. 2005. "Linking Data and Learning: The Grow Network Study.” Journal of Education for Students Placed at Risk 10 (3): 241267.

Codding, Robin S., and James E. Connell, Jr. 2009. "Preparing Educators to Effectively Use Curriculum-Based Measurement.” In Handbook of Data-Based Decision

Making in Education, edited by Theodore J. Kowalski and Thomas J. Lasley II, 136-152. New York: Routledge.

Copland, Michael A., Michael S. Knapp, and Juli A. Swinnerton. 2009. "Principal leadership, data, and school improvement." In Handbook of Data-Based Decision Making in Education, edited by Theodore J. Kowalski and Thomas J. Lasley II, 153-172. New York: Routledge.

Data Quality Campaign. 2010. “10 Essential Elements of a State Longitudinal Data System.” Accessed March 3. http://www.dataqualitycampaign.org/survey/ele ments.

Datnow, Amanda, and Vicki Park. 2009. "School System Strategies for Supporting Data Use.” In Handbook of Data-Based Decision Making in Education, edited by Theodore J. Kowalski and Thomas J. Lasley II, 191-206. New York: Routledge.

Datnow, Amanda, Vicki Park, and Priscilla Wohlstetter. 2007. Achieving with Data: How High-Performing School Systems Use Data to Improve Instruction for Elementary Students. Los Angeles: University of Southern California Center on Educational Governance.

Duncan, Arne. 2010. "Unleashing the Power of Data for School Reform." Speech at STATS DC 2010 Data Conference. Accessed February 12, 2011. http://www. ed.gov/news/speeches/unleashing-power-data-school-reform-secretary-arneduncans-remarks-stats-dc-2010-data-.

Gallagher, Lawrence, Barbara Means, and Christine Padilla. 2008. Teachers'Use of Student Data Systems to Improve Instruction 2005 to 2007. Washington: US Department of Education.

Hamilton, Laura, Richard Halverson, Sharnell S. Jackson, Ellen Mandinach, Jonathan A. Supovitz, and Jeffrey C. Wayman. 2009. Using Student Achievement Data to Support Instructional Decision Making (NCEE No. 2009-4067). Washington: US Department of Education.

Ingram, Debra, Karen Seashore Lewis, and Roger G. Schroeder. 2004. "Accountability Policies and Teacher Decision Making: Barriers to the Use of Data to Improve Practice." Teachers College Record 106(6): 1258-1287.

Lasley, Thomas J. 2009. "Using Data to Make Critical Choices.” In Handbook of DataBased Decision Making in Education, edited by Theodore J. Kowalski and Thomas J. Lasley II, 243-258. New York: Routledge.

Marzano, Robert J. 2009. "Formative Versus Summative Assessments as Measures of Student Learning." In Handbook of Data-Based Decision Making in Education, edited by Theodore J. Kowalski and Thomas J. Lasley II, 259-271. New York: Routledge.

McCrummen, Stephanie. 2010. "D.C. principal's hands-on tack transforms Sousa Middle but also ruffles feathers." Washington Post, June 7.

Means, Barbara, Christine Padilla, and Larry Gallagher. 2010. Use of Education Data at 
the Local Level. Washington, DC: US Department of Education.

National Center for Education Statistics. 1997. Basic Data Elements for Elementary and Secondary Education Information Systems (NCES 97-531). Washington: National Forum on Education Statistics.

Supovitz, Jonathan A., and Valerie Klein. 2003. Mapping a Course for Improved Student Learning: How Innovative Schools Systems Actually Use Student Performance Data to Guide Improvement. Philadelphia: Consortium for Policy Research in Education, University of Pennsylvania Graduate School of Education.

Wayman, Jeffery C. 2005. "Involving Teachers in Data-Driven Decision Making: Using Computer Data Systems to Support Teacher Inquiry and Reflection.” Journal of Education for Students Placed at Risk 10 (3): 295-308.

Wayman, Jeffery C., and Vincent Cho. 2009. "Preparing Educators to Effectively Use Student Data Systems." In Handbook of Data-Based Decision Making in Education, edited by Theodore J. Kowalski and Thomas J. Lasley II, 89-103. New York: Routledge.

Wayman, Jeffery C., Sam Stringfield, and Mary Yakimowski. 2004. Software Enabling School Improvement Through Analysis of Student Data. Baltimore: Center for Research on the Education of Students Placed At Risk, Johns Hopkins University.

Zavadsky, Heather. 2009. "Building Data-Driven District Systems.” In Handbook of Data-Based Decision Making in Education, edited by Theodore J. Kowalski and Thomas J. Lasley II, 173-190. New York: Routledge. 


\section{Notes:}

1. In addition to the three commercial systems studied, a survey of the market at the time of the study found the following nationally-competitive education data systems: Ed Plan from PCG Education, TetraData from Follett, Inform from EDmin, Inform from Pearson, STARS from School City, Student Achievement Management System from Executive Intelligence, and Infinite Campus.

2. The survey invitation was posted as a link on the SchoolNet login portal; 30 users (of approximately 500 teachers in the district) chose to participate in the survey. The majority (62 percent) were elementary teachers and had been teaching for more than 10 years (74 percent).

Rebecca Hinze-Pifer is a second year Master of Public Policy student at The George Washington University concentrating in education policy, and will be starting a doctoral program in the fall. Rebecca has worked at the Pew Research Centers and was a public school teacher for seven years. She earned her BA from the University of WisconsinMadison.

Daniel S. Ramsey is a second year Master of Public Policy student at The George Washington University concentrating in budgeting and public finance and education policy. Daniel has worked in institutional research and assessment at California State University, Fullerton, The George Washington University, and at the US Government Accountability Office. He earned his BA from California State University, Fullerton.

The authors thank Rachel Brody, Alicia Mazzara, Andrea Leung, and Kaitlin Welborn for their thoughtful reviews and editorial work. They would also like to thank Patrick Sherrill for his vision for the initial evaluation project and Dr. Kathryn Newcomer for her guidance during the original project as well as the process of preparing the report for publication. Finally, the authors would like to thank Amy Hinze-Pifer, Marjorie Hannon Pifer, Richard Pifer, Christine Hernandez, Dennis Ramsey, and Mary Anne Ramsey for their support through the process of publishing and their other graduate school endeavors. 